\title{
The relationship between stress, social capital and quality of education among medical residents
}

\author{
Charis Anastasiadis ${ }^{1}$, Andreas Tsounis ${ }^{2}$ and Pavlos Sarafis ${ }^{3^{*}}$ (1)
}

\begin{abstract}
Objective: The educational climate is a key factor in medical education. The study aims to examine the relationship between trainee doctors' perceptions of hospital educational environment, stress and social capital. A cross-sectional study among 104 trainee doctors working in a Greek public hospital was conducted. According to the main hypotheses, perceptions of clinical training are positively associated with social capital and negatively with stress.

Results: Perceptions of autonomy dimension of training quality was positively related to community participation, tolerance of diversity and total social capital. Perceptions of teaching and social support dimensions of the quality of education were positively correlated with community participation. All training quality subscales were negatively correlated with almost all working stress subscales. Analysis revealed significantly higher scores in autonomy perceptions for those who evaluated their undergraduate studies positively. Females had a significantly lower score in perceptions of teaching and social support scales.
\end{abstract}

Keywords: Hospital, Quality of education, Residents, Social capital, Stress

\section{Introduction}

The educational environment is as a key element for the quality of medical education [1]. The World Federation for Medical Education has mentioned as the most important components of the educational environment: the atmosphere, the learning opportunities and the availability of facilities [2]. Other researchers distinguish between physical environment (safety, shelter and other facilities), emotional climate (social support, absence of harassment) and intellectual climate (active participation, evidence-based learning) [3].

The transition to the hospital is stressful for most junior doctors. Long working hours, inadequate support from senior staff, new responsibilities, job insecurity and the fact that their mistakes are highly visible are among the most common stressors $[4,5]$.

\footnotetext{
*Correspondence: pavlos.sarafis@cut.ac.cy

${ }^{3}$ Department of Nursing, School of Health Sciences, Cyprus University

of Technology, 15, Vragadinou Str, 3041 Limassol, Cyprus

Full list of author information is available at the end of the article
}

Job and personal resources may buffer job demands that may lead to high-stress levels for junior doctors [5]. Job demands are these organizational factors that require constant physical and psychological effort. Job resources are the psychological, social and organizational aspects of work (e.g. autonomy, supervisory coaching). Personal recourses are those psychological and social elements that contribute to an individuals' ability to control and impact on his/her environment successfully $[6,7]$. Social capital (SC) is a resource on both individual and ecological level that may contribute to stress reduction and junior doctors' adaptation to the educational environment.

SC is defined as "those features of social structuressuch as interpersonal trust and norms of reciprocity and mutual aid-which act as resources for individuals and facilitate collective action" [8]. SC may help individuals', groups' and organizations' function by enabling cooperative ventures and facilitating interpersonal interactions [9].

SC main theoretical approaches are the individualistic and the collective. According to the individualistic 
approach, people benefit from participating in social networks by gaining access to informational, emotional and verbal support [10]. In the collective approach, the emphasis is given to the group or to the community. Communities or organizations rich in social interactions have better economic, health and social indices [11].

The main distinction concerning its' types is made between cognitive and structural SC [12]. Cognitive refers to perceptions, shared values, beliefs, and attitudes like trust, reciprocity, and tolerance. Structural SC refers to the way that people act in their social environment (e.g. level of participation, number of networks) [13]. Another distinction, based in the type of the connections, is between bonding (informal networks of strong ties, like family), bringing (informal networks of weaker ties like colleagues) and linking (formal networks) SC [14]. In both distinctions, the capacity of the individuals acting together and the potential of this cooperation is evaluated [15].

SC has beneficial effects for both individuals and organizations. Literature suggests an inverse relationship between higher SC and mental disorders [16]. Additionally, it is positively associated with educational attainment [17] and achievement [18]. In organizational studies, SC is positively related with job satisfaction $[9$, $19]$ and negatively with emotional exhaustion and turnover intention [20].

The theoretical model of the study is based on Job Demands-Resources theory according to which personal resources may buffer stress provoked from job demands [7]. The current study investigates the relation between trainee doctors' perceptions of the hospital educational environment, stress and their SC. SC was treated as an ecological resource which was measured on individual level. Both its' cognitive (e.g. feelings of safety) and structural (e.g. family, friends and work connections) elements were evaluated. According to our main hypotheses, residents' positive perceptions of the educational environment are negatively associated with stress and positively with higher SC levels.

\section{Main text \\ Methods \\ Participants and procedure}

The study was conducted in "Konstantopoulio" General Hospital in Athens. In total, 149 anonymous questionnaires were distributed to all trainee doctors. The final sample consisted of 104 participants (Response Rate: $69.8 \%$ ). The participants were informed on the purpose of the study and on confidentiality and they were free to participate, refuse or withdraw at any time.

\section{Measures}

A self-administrated questionnaire was used. At the first part, it contained questions recording socio-demographics and information concerning training, specialty, years of internship in the specific position and in total and satisfaction concerning internship.

Residents undergraduate education was evaluated with three questions ranked on a 6-point scale.

Residents' SC was assessed by the Greek, validated, version of Social Capital Questionnaire (SCQ-G) [21]. SCQ-G is a 36 item ranked on a 4-point scale, with six subscales: (i) Local community participation; (ii) Feelings of safety; (iii) Family/friends connections; (iv) Value of life and social agency; (v) Tolerance of diversity; and (vi) Work connection. Higher scores indicate more SC.

Perceptions about the educational environment were assessed by the Greek, validated, version of Postgraduate Hospital Educational Environment Measure (PHEEM-G) [22]. PHEEM-G measures three domains of the clinical learning environment: (i) Perceptions of autonomy; (ii) Perceptions of teaching; (iii) and Perceptions of social support. It consists of 40 questions, ranked on a 5-point scale. Two opened type questions, concerning the satisfaction with the internship's position and the expectations' implementation were added during its' validation process [22].

Stress was measured with Sources of Stress Scale (SSS) [23]. It consists of a total of 60 items measuring five dimensions: (i) Uncontrollable work situation; (ii) The organization of work and working conditions; (iii) Work-family conflict; (iv) Unfavorable relationships with colleagues; and (v) Interaction with patients. Each item ranked on a 3-point scale measuring the frequency and a 4-point scale measuring the tension of specific sources of stress.

\section{Statistical analysis}

Pearson's coefficients were used exploring association of two continuous variables. Multiple linear regression analysis was used to dependent the training quality subscales. The regression equation included terms for sample characteristics as well as for SC and stress scales. Adjusted regression coefficients $(\beta)$ with standard errors (SE) were computed. A stepwise method was used. All the reported $\mathrm{p}$ values were two-tailed. Analyses were conducted using SPSS (version 19.0).

\section{Results}

The sample consisted of 104 medical interns with mean age 34.4 years old. Most of the participants were males (57.7\%). Mean internship duration at the current site was 2.4 years and in general was 3.3 years. All the participants 
attended a full time residency in their current position. Concerning specialty, $23.1 \%$ were trained as pathologists, $15.4 \%$ as surgeons, $13.5 \%$ as general practitioners, $13.5 \%$ as radiologists, $6.7 \%$ as cardiologists, an equal percentage of $5.8 \%$ as obstetricians, urologists and orthopaedics, while $10.7 \%$ attended other specialties. Most of them (64.4\%) have studied in Greece. More than half of the participants $(51.9 \%)$ were satisfied with their current internship. Also, 34.6\% of the participants agreed with the statement "My expectations I had when I started Medical school are fulfilled", $55.8 \%$ with the statement "Medical school qualified me for dealing with the internship demands", $39.4 \%$ with the statement "Starting my internship, I was already capable of dealing with daily clinical skills" and 50.0\% with the statement "My undergraduate studies helped me in having better communication with my patients".

Participants' scores in all scales are presented in Table 1. Mean total SC score was 2.27. For the stressrelated factors, mean scores for the frequency subscales ranged from 0.95 to 1.31 and for the intensity subscales ranged from 1.36 to 1.74 . As far as training quality is concerned, the mean score for perceptions of autonomy was 23.98, for perceptions of teaching it was 28.45 and for perceptions of social support it was 21.04.

Perceptions of autonomy scale was positively correlated with "Community Participation", "Tolerance to Diversity" subscales and total SC score (Table 2). Thus, higher values in the aforementioned scores are associated with greater autonomy perceptions. Also, perceptions of teaching scale was positively correlated with "Community Participation" and perceptions of social support scale was positively correlated with "Community Participation" and total SC score. Also, all three training quality subscales were negatively correlated with almost all working stress subscales (frequency and intensity), indicating that participants' less working stress is associated with greater satisfaction from their training.

When multiple linear regression was applied, significantly higher scores in Perceptions of Autonomy were found in those participants who were satisfied with their current internship, believed that their undergraduate

Table 1 Study scales descriptive

\begin{tabular}{|c|c|c|}
\hline & Mean (SD) & Cronbach's a \\
\hline \multicolumn{3}{|l|}{ Social capital } \\
\hline Participation in the community & $1.70(0.30)$ & 0.73 \\
\hline Value of life and social agency & $2.63(0.36)$ & 0.76 \\
\hline Feelings of safety & $2.41(0.57)$ & 0.72 \\
\hline Family and friend relationships & $2.43(0.44)$ & 0.81 \\
\hline Tolerance to diversity & $2.30(0.56)$ & 0.88 \\
\hline Work relationships & $2.67(0.53)$ & 0.76 \\
\hline Total SC & $2.27(0.25)$ & 0.78 \\
\hline \multicolumn{3}{|l|}{ Uncontrollable work situations } \\
\hline Frequency & $1.15(0.27)$ & 0.72 \\
\hline Intensity & $1.74(0.54)$ & 0.87 \\
\hline \multicolumn{3}{|c|}{ The organization of work and working conditions } \\
\hline Frequency & $1.31(0.27)$ & 0.70 \\
\hline Intensity & $1.66(0.63)$ & 0.90 \\
\hline \multicolumn{3}{|l|}{ Conflict of work and family roles } \\
\hline Frequency & $1.31(0.30)$ & 0.73 \\
\hline Intensity & $1.54(0.60)$ & 0.85 \\
\hline \multicolumn{3}{|c|}{ Unfavorable relationships with colleagues } \\
\hline Frequency & $0.95(0.29)$ & 0.72 \\
\hline Intensity & $1.40(0.54)$ & 0.80 \\
\hline \multicolumn{3}{|l|}{ Interaction with patients } \\
\hline Frequency & $1.22(0.36)$ & 0.72 \\
\hline Intensity & $1.36(0.57)$ & 0.77 \\
\hline \multicolumn{3}{|l|}{ Training quality } \\
\hline Perceptions of autonomy & $23.98(8.85)$ & 0.83 \\
\hline Perceptions of teaching & $28.45(10.72)$ & 0.90 \\
\hline Perceptions of social support & $21.04(5.89)$ & 0.71 \\
\hline
\end{tabular}


Table 2 Correlation coefficients between training quality scales and social capital and working stress scales

\begin{tabular}{|c|c|c|c|}
\hline & Perceptions of autonomy & Perceptions of teaching & $\begin{array}{l}\text { Perceptions } \\
\text { of social } \\
\text { support }\end{array}$ \\
\hline \multicolumn{4}{|l|}{ Social capital } \\
\hline Participation in the community & $0.28^{* *}$ & $0.26^{* *}$ & $0.29^{* *}$ \\
\hline Value of life and social agency & 0.13 & -0.03 & 0.13 \\
\hline Feelings of safety & 0.10 & 0.12 & 0.16 \\
\hline Family and friend relationships & 0.13 & 0.16 & 0.16 \\
\hline Tolerance to diversity & $0.22^{*}$ & -0.01 & 0.17 \\
\hline Work relationships & -0.01 & -0.01 & 0.05 \\
\hline Total SC & $0.24^{*}$ & 0.10 & $0.25^{*}$ \\
\hline \multicolumn{4}{|l|}{ Working stress } \\
\hline \multicolumn{4}{|l|}{ Uncontrollable work situations } \\
\hline Frequency & $-0.21^{*}$ & -0.08 & -0.18 \\
\hline Intensity & $-0.27^{* *}$ & $-0.30^{* *}$ & $-0.26^{* *}$ \\
\hline \multicolumn{4}{|c|}{ The organization of work and working conditions } \\
\hline Frequency & $-0.36^{* * *}$ & $-0.34^{* * *}$ & $-0.41^{* * *}$ \\
\hline Intensity & $-0.34^{* * *}$ & $-0.37^{* * *}$ & $-0.32^{* *}$ \\
\hline \multicolumn{4}{|l|}{ Conflict of work and family roles } \\
\hline Frequency & $-0.26^{* *}$ & $-0.23^{*}$ & $-0.24^{*}$ \\
\hline Intensity & $-0.29^{* *}$ & $-0.36^{* * *}$ & -0.14 \\
\hline \multicolumn{4}{|c|}{ Unfavorable relationships with colleagues } \\
\hline Frequency & $-0.35^{* * *}$ & $-0.23^{*}$ & $-0.30^{* *}$ \\
\hline Intensity & $-0.43^{* * *}$ & $-0.41^{* * *}$ & $-0.29^{* *}$ \\
\hline \multicolumn{4}{|l|}{ Interaction with patients } \\
\hline Frequency & -0.08 & 0.02 & -0.11 \\
\hline Intensity & -0.17 & $-0.28^{* *}$ & $-0.27^{* *}$ \\
\hline
\end{tabular}

${ }^{*} \mathrm{p}<0.050 ;{ }^{* *} \mathrm{p}<0.010 ;{ }^{* * *} \mathrm{p}<0.001$

studies helped them to have better communication with patients, feel that Medical school qualified them for dealing with the internship demands and their expectations from Medical school were fulfilled (Table 3). Also, greater values in SC total score and lower values in frequency subscale of "The organization of work and working conditions" and in intensity subscale of "Unfavorable relationships with colleagues" are associated with higher scores in Perceptions of Autonomy scale.

Females had a significantly lower score in perceptions of teaching scale compared to males. Moreover, higher scores in perceptions of teaching were found in participants who were satisfied with their current internship and indicated that the expectations from Medical school were fulfilled. The greater score in "Community Participation" and lower values in frequency subscale of "The organization of work and working conditions" and in intensity subscale of "Unfavorable relationships with colleagues" were associated with higher perceptions of teaching scores.

Females had a significantly lower score in perceptions of social support compared to males. Moreover, higher scores in perceptions of social support were found in participants who were satisfied with their current internship. Greater values in SC total score and lower values in "The organization of work and working conditions" were associated with higher scores in perceptions of social support.

\section{Discussion}

The study investigated the relationship between medical residents' perceptions of hospital educational environment, stress and SC. The results revealed a negative view of one's role concerning perceptions of autonomy, need of some retraining for teaching perceptions and a perception of a not pleasant place for social support climate, according to PHEEM cut-off scores [1, 22]. Moreover, $68 \%$ of the participants declared that their expectations from Medical school were not fulfilled. The above is consistent with previous findings. According to the results of a study amongst 731 trainees from different Greek hospitals, residents were generally dissatisfied with the educational environment, while the expectations they had when they entered medical school were not covered [24]. 
Table 3 Multiple linear regression results with training quality subscales as dependent variables

\begin{tabular}{|c|c|c|c|}
\hline & $\beta^{a}$ & $\mathrm{SE}^{\mathbf{b}}$ & $\mathbf{P}$ \\
\hline \multicolumn{4}{|l|}{ Perceptions of autonomy } \\
\hline \multicolumn{4}{|l|}{ In general, I am very satisfied with my internship in the current site } \\
\hline Disagree & $0.00^{c}$ & & \\
\hline Agree & 4.53 & 1.54 & 0.004 \\
\hline \multicolumn{4}{|c|}{ My undergraduate studies helped me in having better communication with my patients } \\
\hline Disagree & 0.00 & & \\
\hline Agree & 4.49 & 1.34 & 0.001 \\
\hline \multicolumn{4}{|c|}{ Med school qualified me for dealing with the demands of my internship } \\
\hline Disagree & 0.00 & & \\
\hline Agree & 3.91 & 1.41 & 0.007 \\
\hline \multicolumn{4}{|l|}{ My expectations I had when I started Med school are fulfilled. } \\
\hline Disagree & 0.00 & & \\
\hline Agree & 3.76 & 1.56 & 0.018 \\
\hline Total SC & 8.42 & 3.39 & 0.007 \\
\hline The organization of work and working conditions (frequency) & -11.64 & 2.92 & $<0.001$ \\
\hline Unfavorable relationships with colleagues (intensity) & -4.66 & 1.27 & $<0.001$ \\
\hline \multicolumn{4}{|l|}{ Perceptions of teaching } \\
\hline \multicolumn{4}{|l|}{ Sex } \\
\hline Males & $0.00^{c}$ & & \\
\hline Females & -5.83 & 1.38 & $<0.001$ \\
\hline \multicolumn{4}{|l|}{ In general, I am very satisfied with my internship in the current site } \\
\hline Disagree & 0.00 & & \\
\hline Agree & 8.46 & 1.57 & $<0.001$ \\
\hline \multicolumn{4}{|l|}{ My expectations I had when I started Med school are fulfilled } \\
\hline Disagree & 0.00 & & \\
\hline Agree & 4.42 & 1.56 & 0.006 \\
\hline Participation in the community & 8.40 & 2.33 & $<0.001$ \\
\hline The organization of work and working conditions(frequency) & -13.83 & 3.65 & $<0.001$ \\
\hline Unfavorable relationships with colleagues (intensity) & -5.87 & 1.31 & $<0.001$ \\
\hline \multicolumn{4}{|l|}{ Perceptions of social support } \\
\hline \multicolumn{4}{|l|}{ Sex } \\
\hline Males & $0.00^{c}$ & & \\
\hline Females & -2.44 & 1.01 & 0.017 \\
\hline \multicolumn{4}{|l|}{ In general, I am very satisfied with my internship in the current site. } \\
\hline Disagree & 0.00 & & \\
\hline Agree & 2.42 & 1.04 & 0.022 \\
\hline Total SC & 6.02 & 1.96 & 0.003 \\
\hline The organization of work and working conditions (frequency) & -7.35 & 1.87 & $<0.001$ \\
\hline
\end{tabular}

a Regression coefficient

b Standard error

c Indicates reference category

Our study provided empirical support for the existence of stress among residents. Stress symptoms frequency was between moderate and high levels in all SSS subscales, except unfavorable relationships with colleagues which were moderate. As far as the symptoms intensity, this was in medium levels. This complies with other researchers' findings in Greece. A study on occupational stress amongst 355 Greek trainee doctors showed that they expressed significantly higher levels of stress than other professionals [4]. Findings from other countries' studies confirm occupational stress among residents $[5$, $25,26]$.

Analysis revealed statistically significant associations between almost all PHEEM and stress dimensions. In all 
cases, higher frequency and intensity of stress symptoms was positively associated with the negative clinical environment evaluation. The fact that stress is typical during the residency period is well-documented in the literature [27].

The findings indicate a significant positive correlation between total SC and Perceptions of autonomy and social support dimensions of PHEEM. Additionally, Participation in the Community was positively related with all three PHEEM dimensions, and "Tolerance to Diversity" to perceptions of autonomy subscale. The absence of similar studies makes the comparison with previous findings impossible. However, results are in line with SC theory basic assumptions. Higher SC levels may influence individuals' tendency for autonomy and providing and taking social support, and therefore their perceptions of autonomy and supportiveness opportunities [28, 29]. For example, an active actor in the local community maintains this tendency is the working environment, which in turn may lead to greater opportunity to reach higher levels of autonomy and social support.

In summary, findings suggest that medical residents perceptions concerning their educational environment are negatively associated with almost all stress subscales. Preliminary evidence suggests that higher levels of SC are associated with the positive evaluation of their educational experience. Further research, regarding both individuals' and organizations' SC on trainees perceptions, is suggested.

\section{Limitations}

- The study was cross-sectional, so the results cannot be generalized.

- Participants were selected on the basis of convenience.

- The sample size was relatively small.

- Only individual SC was measured. It would be helpful to be treated both as an organizational resource (SC of the hospital).

\section{Abbreviations}

SCQ: Social Capital Questionnaire; PHEEM: Postgraduate Hospital Educational Environment Measure; SSS: Sources of Stress Scale; SC: social capital.

\section{Authors' contributions \\ CA conceived the study, collected data and performed statistical analysis. AT drafted the manuscript and contributed to data analysis. PS participated in the study design, helped to draft the manuscript and revised it critically. All authors read and approved the final manuscript.}

\section{Author details}

1 "Konstantopoulio" General Hospital of Nea Ionia, Athens, Greece. ${ }^{2}$ School of Psychology, The Aristotle University of Thessaloniki, Thessaloniki, Greece. ${ }^{3}$ Department of Nursing, School of Health Sciences, Cyprus University of Technology, 15, Vragadinou Str, 3041 Limassol, Cyprus.

\section{Acknowledgements}

The authors would like to thank all the medical residents for their participation in the study.

\section{Competing interests}

The authors declare that they have no competing interests.

\section{Availability of data and materials}

A confidentiality agreement with participants prevents us from sharing the data.

\section{Consent for publication}

Not applicable.

\section{Ethics approval and consent to participate}

The Ethics Committee of "Konstantopoulio" General Hospital granted permission for conducting the research. All the participants were informed on the purpose of the study and on confidentiality and they were free to participate, refuse or withdraw at any time of the procedure. Hence, returning the questionnaire was interpreted as informed consent.

\section{Funding}

There was no funding for this study.

\section{Publisher's Note}

Springer Nature remains neutral with regard to jurisdictional claims in published maps and institutional affiliations.

Received: 13 March 2018 Accepted: 2 May 2018

Published online: 04 May 2018

\section{References}

1. Roff S. Education environment: a bibliography. Med Teach. 2005;27:353-7. https://doi.org/10.1080/01421590500151039.

2. WFME. WFME global standards for quality improvement in medical education: European specifications for basic and postgraduate medical education and continuing professional development. Copenhagen: MEDINE Quality Assurance Task Force, WFME Office: 2007.

3. Mohanna K, Cottrell E, Chambers R, Wall DW. Teaching made easy: a manual for health professionals. Oxford: Radcliffe Medical Press Ltd: 2000

4. Antoniou AS, Davidson MJ, Cooper CL. Occupational stress, job satisfaction and health state in male and female junior hospital doctors in Greece. J Manage Psychol. 2003;18:592-621.

5. Bernburg M, Vitzthum K, Groneberg DA, Mache S. Physicians' occupational stress, depressive symptoms and workability in relation to their working environment: a cross-sectional study of differences among medical residents with various specialties working in German hospitals. BMJ Open. 2016;6:e011369. https://doi.org/10.1136/bmjopen-2016011369.

6. Hobfoll SE. Social and psychological resources and adaptation. Rev Gen Psychol. 2000:6:307-24. https://doi.org/10.1037/1089-2680.6.4.307.

7. Xanthopoulou D, Bakker AB, Demerouti E, Schaufeli WB. Reciprocal relationships between job resources, personal resources, and work engagement. J Vocat Behav. 2009;74:235-44. https://doi.org/10.1016/j. jvb.2008.11.003.

8. Waisel DB. Developing social capital in the operating room: the use of population-based techniques. Anesthesiology. 2005, 103:1305-1310. doi: 0000542-200512000-00026.

9. Ommen O, Driller E, Köhler T, Kowalski C, Ernstmann N, Neumann M, et al. The relationship between social capital in hospitals and physician job satisfaction. BMC Health Serv Res. 2009;16(9):81. https://doi. org/10.1186/1472-6963-9-81.

10. Portes A. Social capital: its origins and applications in modern sociology. Annu Rev Sociol. 1998;24:1-24. https://doi.org/10.1146/annur ev.soc.24.1.1.

11. Putnam RD. The prosperous community: social capital and public life. Am Prospect. 1993;13:35-42. 
12. Kritsotakis G, Vassilaki M, Melaki V, Georgiou V, Philalithis AE, Bitsios P, et al. Social capital in pregnancy and postpartum depressive symptoms: a prospective mother-child cohort study (the Rhea study). Int I Nurs Stud. 2013;50:63-72. https://doi.org/10.1016/j.ijnurstu.2012.08.012.

13. Grootaert C, Bastelaer T. Understanding and measuring social capital: a multidisciplinary tool for practitioners. Washington: World Bank; 2002.

14. Ferlander S. The importance of different forms of social capital for health. Acta Sociol. 2007;50:115-28. https://doi.org/10.1177/0001699307077654.

15. Kwon SW, Adler PS. Social capital: maturation of a field of research. Acad Manag Rev. 2014;39:412-22. https://doi.org/10.5465/amr.2014.0210.

16. De Silva MJ, McKenzie K, Harpham T, Huttly SR. Social capital and mental illness: a systematic review. J Epidemiol Community Health. 2005;59:61927. https://doi.org/10.1136/jech.2004.029678.

17. Israel GD, Beaulieu J. Investing in communities: social capital's role in keeping youth in school. J Community Dev Soc. 2004;34:35-57. https:// doi.org/10.1080/15575330409490111.

18. Israel GD, Beaulieu $L$, Hartless $G$. The influence of family and community social capital on educational achievement. Rural Sociol. 2001;66:43-68. https://doi.org/10.1111/j.1549-0831.2001.tb00054.x.

19. Tsounis A, Niakas D, Sarafis P. Social capital and job satisfaction among substance abuse treatment employees. Subst Abuse Treat Prev Policy. 2017;12(1):8. https://doi.org/10.1186/s13011-017-0093-6.

20. Kowalski C, Ommen O, Driller E, Ernstmann N, Wirtz MA, Köhler T, et al. Burnout in nurses - the relationship between social capital in hospitals and emotional exhaustion. J Clin Nurs. 2010;19:1654-63. https://doi.org/1 0.1111/j.1365-2702.2010.03647.x.

21. Kritsotakis $G$, Koutis AD, Alegakis AK, Philalithis AE. Development of the social capital questionnaire in Greece. Res Nurs Health. 2008;31:217-25. https://doi.org/10.1002/nur.20250.
22. Rammos A, Tatsi K, Bellos S, Dimoliatis ID. Translation into Greek of the postgraduate hospital educational environment measure (PHEEM). Arch Hellen Med. 2011;28:48-56 (in Greek).

23. Gregov L, Kovacevic A, Sliskovic A. Stress among Croatian physicians: comparison between physicians working in emergency medical service and health centers: a pilot study. Croat Med J. 2011;52:8-15. https://doi. org/10.3325/cmj.2011.52.8.

24. Karathanos V, Koutsogiannou P, Bellos S, Kiosses V, Jelastopulu E, Dimoliatis I. How 731 residents in all specialties throughout Greece rated the quality of their education: evaluation of the educational environment of Greek hospitals by PHEEM (postgraduate hospital education environment measure). Arch Hellen Med. 2015;32:743-57 (in Greek).

25. Yokoya S, Seo E, Ogawa R, Takayashiki A, Maeno T. The effect of stressrelated factors on depressive state among medical residents. Med Res Arch. 2017;4:77-87. https://doi.org/10.18103/mra.v4i6.679.

26. Buddeberg-Fischer B, Klaghofer R, Stamm M, Siegrist J, Buddeberg C. Work stress and reduced health in young physicians: prospective evidence from Swiss residents. Int Arch Occup Environ Health. 2008;82:31-8. https://doi.org/10.1007/s00420-008-0303-7.

27. Levey RE. Sources of stress for residents and recommendations for programs to assist them. Acad Med. 2001;76:142-50.

28. Burt RS. Closure as social capital. In: Lin N, Cook K, Burt RS, editors. Social capital: theory and research. New Jersey: Transaction Publishers; 2001.

29. Thompson JA. Proactive personality and job performance: a social capital perspective. J Appl Psychol. 2005;90:1011-7. https://doi. org/10.1037/0021-9010.90.5.1011.
Ready to submit your research? Choose BMC and benefit from:

- fast, convenient online submission

- thorough peer review by experienced researchers in your field

- rapid publication on acceptance

- support for research data, including large and complex data types

- gold Open Access which fosters wider collaboration and increased citations

- maximum visibility for your research: over $100 \mathrm{M}$ website views per year

At BMC, research is always in progress.

Learn more biomedcentral.com/submissions 